\title{
Integração externa, sinônimo de desintegração interna?
}

\author{
RUBENS RICUPERO
}

$\mathrm{Q}$ UAL É A MÃE de todos os "dilemas e desafios" enfrentados pelo Brasil no limiar do terceiro milênio, a causa primeira, determinante senão da totalidade dos nossos problemas, ao menos de boa parte deles? Provavelmente seria perda de tempo tentar responder a essa pergunta, mas não há dúvida de que a questão da integração externa, da inserção na economia globalizada, é forte candidata ao título.

Em termos de problema econômico imediato, nenhum é mais grave do que o déficit comercial e em contas correntes, o estrangulamento do setor externo, perto do qual perderam muito da agudeza desafios anteriores como o controle da inflação, o ajuste fiscal, a reforma cambial, mais ou menos encaminhados.

Em termos históricos, desde Caio Prado Júnior passando por Fernando Novais, aprendemos que foi o "sentido da colonização", isto é, a natureza de colônia de exploração destinada a fornecer produtos tropicais aos mercados de fora que, mais do que outro fator qualquer, fez de nós o que somos hoje.

Seria exagero pretender que, da maneira pela qual se resolva a questão da inserção internacional vai depender a solução de alguns outros impasses? Que ela é uma espécie de "condição de possibilidade" para o encaminhamento desses outros?

Formulei a questão no título em termos de dilema: será que a integração com o mundo significa necessariamente para o país a desintegração consigo mesmo? De que vale ganhar o mundo inteiro se perdermos a alma?

O dilema não é de forma alguma fantasista pois nossa história não é outra coisa do que o processo pelo qual a inserção na economia-mundo acarretou, no território brasileiro, a formação de sociedade pouco integrada. É possível evitar a repetição do padrão do passado num momento de globalização intrusiva, em que parece haver ainda menos alternativa para a integração externa do que a que existiu na maior parte de nossa história? 
Pois, ao contrário do Japão e da China, que lograram viver em relativo isolamento até 200 anos atrás, o que caracteriza a experiência histórica do Brasil, dos Estados Unidos, da Argentina ou da Austrália é que a própria existência desses países é de natureza derivada. Chineses e japoneses constituíam nações definidas muito antes de se verem obrigados a insertar-se na economia dominada pelos europeus. Ao passo que para os países novos, nem se coloca a questão de inserir-

o Brasil será talvez

o único exemplo de país com nome de mercadoria ... se ou não no contexto exterior envolvente, uma vez que não passam do produto da expansão do sistema político-econômico, religiosocultural, da Europa a partir do século XV. Nessa evolução, foi predo-

minante o peso do incipiente capitalismo mercantilista, que se fez sentir até em aspectos inesperados. As terras achadas pelos portugueses acabarão batizadas não pelo critério ideológico-religioso (Vera ou Santa Cruz), mas tomarão emprestado o nome de mercadoria do capitalismo da época; excetuado o caso duvidoso da Argentina, o Brasil será talvez o único exemplo de país com nome de mercadoria...

O princípio orgânico que definiu as estruturas econômica e social das colônias foi o tipo de inserção na economia mundial, a existência de mercado com forte demanda para produtos, como o açúcar, aptos a serem produzidos pelo sistema de plantation, a combinação de escravidão com latifúndio. É por isso que essa modalidade de organização vai implantar-se mais ou menos do mesmo modo não só no Brasil mas nas Antilhas espanholas, francesas, inglesas, holandesas, no Sul dos futuros Estados Unidos, adotada igualmente por colonizadores que diferiam em quase tudo o mais.

A simbiose "mercado externo-escravidão com latifúndio" pode ser melhor captada pelo seu oposto, como em negativo ou espelho, nos Estados Unidos. No Norte, a escravidão chegou a existir mas não vingou por faltar-lhe o oxigênio de que se alimenta: as mercadorias apropriadas ao sistema de plantação e demanda internacional garantida (como o algodão do Sul). Não dispondo de adequadas condições de solo e clima para isso, a Nova Inglaterra e as chamadas Colônias do Meio tiveram de desenvolver-se na base da pequena agricultura, do artesanato e da indústria, buscando impulso dinâmico sobretudo na intermediação comercial mediante o esquema triangular "Norte e Leste americanos - Antilhas-Inglaterra". Por conseguinte, não tanto a escolha como a necessidade plasmou dois tipos diversos de colonização e o que a princípio parecia menos atrativo foi o que, a largo prazo, demonstrou potencial mais sólido de desenvolvimento. É interes- 
sante notar, como dizem Morison \& Commager no clássico The Growth of the American Republic, que em "1698, sete-oitavos do comércio americano da Inglaterra eram feitos com as Antilhas, Virgínia, Maryland e as Carolinas; a Nova Inglaterra e as Colônias do Meio, inclusive a Terra Nova e a Baía de Hudson, representavam apenas um oitavo. Com o passar do tempo e à medida que as Colônias do Norte adquiriram riqueza por meio do comércio com as Antilhas (ênfase minha), esse quadro desigual foi modificado. Por volta de 1747, metade das exportações coloniais da Inglaterra se destinavam às colônias ao norte de Maryland; e em 1767, eram dois terços" (op.cit., v. I: 69). Como se vê, bem antes da Revolução Industrial inglesa, o tipo de colonização chamado de povoamento, por falta de denominação melhor, já havia revelado sua capacidade de promover desenvolvimento qualitativamente superior ao produzido pelas colônias de exploração, apesar do fausto superficial de algumas dessas últimas.

Ninguém, creio, disputa esses fatos. A conclusão é que o gênero de inserção que nos plasmou - e permitiu a perpetuação, muito além da Independência, do padrão colonial "escravidão mais latifúndio" - de um lado integrava o Brasil ao mundo externo, enquanto, do outro, o "desintegrava" internamente, ao dividir a sociedade em senhores e escravos e ao concentrar em poucas mãos a terra, o outro grande fator de produção. Exportando a quase totalidade do açúcar e café que produzia, o Brasil, longe de estar à margem do intercâmbio de mercadorias, encontrava-se nele perfeitamente inserido. Se o país sofreu de alguma coisa, foi de excesso, não de falta de integração ao sistema econômico. Excesso de integração de má qualidade, que dificultou em vez de facilitar sua integração e coesão internas. Convém reter este ponto: ao contrário do que se afirma de maneira superficial, não é qualquer integração que constitui objetivo desejável mas a integração externa que reforça e desenvolve as articulações internas.

\section{O dilema atual}

A existência de alternativas diversas de inserção, umas mais desejáveis que outras, pressupõe alguma margem de escolha entre elas, ainda que mais ou menos condicionada ou limitada por fatores vários. Foi essa margem que o Brasil aproveitou com êxito entre 1930 e 1980, promovendo a industrialização e a articulação de um mercado nacional no contexto do tipo de integração internacional de que então desfrutava, com forte dependência do café e das vantagens ou desvantagens acarretadas por essa situação. Esgotado 
esse caminho tanto por razões internas como pelas ligadas à intensificação da globalização, a questão que se impõe agora é indagar se as limitações derivadas desta última eliminam a possibilidade de opção e ditam um modelo único de inserção que pode agravar nossos já agudos problemas de desigualdade.

Ninguém definiu melhor o dilema que

ninguém definiu melhor o dilema que Celso Furtado ...
Celso Furtado, em A Construção Interrompida, há 10 anos atrás: "A partir do momento em que o motor do crescimento deixa de ser a formação do mercado interno para ser a integração com a economia internacional, os efeitos de sinergia gerados pela interdepen-

dência das distintas regiões do país desaparecem, enfraquecendo consideravelmente os vínculos de solidariedade entre elas (...) o esvaziamento dos sistemas decisórios nacionais será de conseqüências imprevisíveis para a ordenação política de vastas áreas do mundo (...) a predominância da lógica das empresas transnacionais na ordenação das atividades econômicas conduzirá quase necessariamente a tensões inter-regionais (...) tudo apontando para a inviabilização do país como projeto nacional".

Nessa descrição, os pólos alternativos das antinomias estão bem contrastados. Em termos do impulso dinâmico para o crescimento, a escolha seria entre a "formação do mercado interno" ou a "integração com a economia internacional". No que se refere à busca de sinergia ou de ganhos resultantes do aumento da interdependência, deve-se privilegiar as regiões dentro de um espaço nacional ou entre cada uma delas e áreas estrangeiras? Em relação ao comando, indagar se deve ficar com os "sistemas decisórios nacionais" ou com a "lógica das empresas transnacionais".

A preocupação com a nitidez das distinções pode ser enganadora e criar a impressão de que se está sempre diante de situações do tipo "ou uma ou outra" quando, no mais das vezes, seria talvez possível conciliar os dois elementos em proporções variáveis. Salvo em matéria do poder decisório, que não deveria escorregar das mãos do Estado como condição para fazer prevalecer o interesse coletivo sobre o dos acionistas das empresas.

Se assim é em tese, como seria na prática, no mundo de nossos dias? De que espaço se dispõe ainda para a autonomia dos "sistemas decisórios nacionais"?

Faz sentido falar em "projeto nacional"? E, caso esse projeto tenha necessariamente de passar pela integração ao sistema mundial, existiria margem de escolha quanto às modalidades, ao ritmo e à seqüência da inserção ou temos de aceitar uma fórmula única, resultante do "pensamento único"? 


\section{A variedade das respostas}

Não há muito que se possa acrescentar aos argumentos teóricos bastante conhecidos sobre os limites e condicionamentos impostos pela globalização e o grau de autonomia que apesar disso sobrevive. Uma abordagem empírica seria possivelmente mais interessante. Ela mostraria, do ponto de vista histórico, que em situações até certo ponto comparáveis no passado, os caminhos foram quase tão numerosos como os países que os percorreram. A propagação da Revolução Industrial além da Inglaterra, primeiro na Europa Ocidental e nos Estados Unidos, em seguida no Japão, recentemente na Coréia e nos neo-industrializados da Ásia, não replicou o modelo britânico e quase nunca repetiu fórmulas idênticas.

O mesmo pode ser dito da variedade de maneiras pelas quais os países se esforçam hoje para responder ao desafio da inserção na economia globalizada. A realidade da qual se deve partir é que existem no mundo cerca de 200 Estados, isto é, centros de decisão com maior ou menor poder e autonomia, 150 dos quais criados no século XX. Não obstante, como sublinha Hobsbawm, três quartos da população da Terra vivem em 25 Estados de 50 milhões de habitantes ou mais cada.

Desse total, um número muito menor se qualificaria para a categoria que George Kennan denominou de "países-monstros", os que aliam um território continental a uma população gigantesca, próxima de 200 milhões ou além dessa cifra. Não basta preencher um dos requisitos, só território, como o Canadá e a Austrália ou apenas população, como o Japão. Ambos são necessários porque a designação de "monstros" não é meramente uma metáfora mas se refere ao extremo grau de heterogeneidade e complexidade decorrentes não só da soma aritmética mas da interação entre gente e espaço. De maneira rigorosa, Kennan admite cinco "monstros": Estados Unidos, Rússia, China, Índia e Brasil. Com alguma boa vontade, pode-se aceitar a União Européia, que constitui uma unidade comercial em relação ao resto do mundo e não tem barreiras internas, e a Indonésia, com seu formigueiro humano espalhado em milhares de ilhas.

É óbvio que as oportunidades e os riscos, as possibilidades e as limitações da globalização não podem ser iguais ou comparáveis para os paísesmonstros, em um extremo, e para as cidades-Estados, Cingapura, Hong Kong, no outro, sem falar dos micro-Estados que vivem de emitir selos ou alugar o nome à Internet, quando não se convertem em paraísos fiscais.

Para nós, a comparação que conta é com os desmesuradamente grandes, não com todos, com os Estados Unidos e a Europa, por exemplo, inventores e beneficiários da globalização, que já estavam integrados interna- 
mente como sistemas de produção e comercialização antes dela, mas com os outros, os que partilham o desafio de adaptar seus projetos nacionais às novas condições criadas por esse fenômeno. Dentre esses últimos, os que vêm crescendo mais aceleradamente são China e Índia, enquanto a Indonésia se debate na crise político-econômica desencadeada pelos problemas financeiros asiáticos de 1997, o Brasil custa a encontrar o caminho de um crescimento estável e sustentado a velocidade satisfatória e a Rússia continua a fechar o pelotão, sem enxergar luz de esperança no escuro subterrâneo em que mergulhou desde a desintegração da União Soviética.

Esses destinos contrastantes demonstram a diversidade de respostas possíveis a um desafio comum. Se dúvida houvesse a esse respeito, ela seria dissipada pelo desempenho oposto do melhor e do pior aluno da classe, a China e a Rússia, os dois exemplos mais representativos das antigas economias socialistas de planificação centralizada empenhadas na mesma transição para uma economia reconstruída, mas com métodos e resultados em tudo e por tudo diferentes. A transição chinesa a princípio foi buscar seu dinamismo econômico na liberalização do setor rural, o impulso interno de que falava Celso Furtado. Só depois, a dimensão externa passa a fazer sentir seu efeito dinamizador até converter a China numa das melhores demonstrações da capacidade de crescer mediante o aproveitamento das oportunidades oferecidas pela globalização para exportações baseadas no baixo custo de mão-de-obra e nos investimentos da diáspora chinesa. Ao contrário do russo, o processo chinês nunca escapou ao controle da liderança, nem seguiu os imprudentes conselhos de países e organizações financeiras ocidentais em favor de uma transformação súbita, o tratamento de choque do Big Bang. Como observou Joseph Stiglitz, em certos aspectos, o governo chinês fez o contrário do aconselhado pelo Consenso de Washington, o que não o impediu de ostentar os mais altos índices de crescimento do mundo durante 20 anos.

\section{Uma história de sucesso diferente}

Não quer isso dizer que o "modelo chinês", a particular mistura de instituições políticas e orientações econômicas seguidas por Beijing, seja recomendável a outros. A Índia, por exemplo, vem se expandindo há anos a taxas entre 6 e 7\%, sem abandonar a democracia parlamentar, com exportações que representam apenas $8 \%$ do PIB. 
Há até um debate entre os economistas hindus sobre a possibilidade de que seu país venha a ser o primeiro a encarnar a possibilidade do desenvolvimento por meio da "nova economia" do conhecimento e dos serviços, em lugar de reproduzir o esquema baseado na exportação de manufaturas, chave do êxito da China e dos tigres asiáticos.

A vantagem comparativa hindu não está numa força de trabalho barata e relativamente bem-educada (a população continua com altos índices de analfabetismo e baixa educação primária), mas numa elite altamente preparada em ciência e tecnologia e ainda com modestas expectativas salariais. O resultado é uma clara vantagem competitiva em atividades econômicas intensivas em conhecimento, não só software mas produtos farmacêuticos e outros.

\section{Viva a diferença}

O caso da Índia serve para mostrar que o desafio da globalização não elimina a possibilidade de soluções diversificadas. É preciso sempre partir da vantagem específica. Para Cingapura, foi a localização geoeconômica que lhe possibilitou converter-se no pólo de transporte e comunicações entre a Ásia do Leste e do Sudeste e o resto do mundo. Para Hong Kong, foi a condição de porta da China. Para essas cidades-Estados, onde o comércio exterior representa mais de $130 \%$ do PIB (devido ao peso da intermediação comercial), para pequenos Estados, como os Países Baixos e a Bélgica, a integração plena na economia globalizada constitui a solução, não o problema. Não é a mesma, todavia, a situação dos países continentais, para os quais a inserção externa tem de levar em conta fatores como a integração interna de regiões heterogêneas. Variam muito as particularidades em cada caso. Só não varia a importância da capacidade da liderança política em formular e aplicar políticas públicas. No fundo, a diferença entre fracasso e êxito está na political craftmanship, na competência e destreza da direção, regulação e coordenação dos governos. Em outros termos, o desafio do desenvolvimento é o de adquirir o conhecimento de como administrar sistemas sociais cada vez mais sofisticados e complexos, o que envolve não só a economia, mas a eqüidade distributiva, os direitos humanos, o meio-ambiente, a participação na cultura.

Trata-se, em última análise, de deduzir as conseqüências práticas do que estava sugerido no livro citado de Celso Furtado: "um sistema econômico nacional não é outra coisa senão a prevalência de critérios políticos que permitem superar a rigidez da lógica econômica na busca do bem-estar coletivo". 


\section{Lições do êxito}

Não parecem ter razão os pessimistas radicais, negadores da possibilidade de conciliar globalização e desenvolvimento, recusando a evidência do crescimento da China e de outros asiáticos. No extremo oposto, tampouco acertam os globalizadores eufóricos para os quais mais valem 10 ou 12 êxitos relativos do que 150 casos difíceis. Os integrantes da dúzia de histórias de sucesso - tigres asiáticos, China, Índia, Chile, talvez México - são diferentes em quase tudo, da importância da agricultura (essencial na Tailândia, nula em Hong Kong), passando pelo grau de abertura (quase total neste último, limitada na Índia e na China), até o papel do capital estrangeiro (central em Hong Kong e Cingapura, modesto na Coréia e em Taiwan). O que têm eles em comum? Além de um mínimo de estabilidade política e macroeconômica (inflação baixa, déficits orçamentários moderados ou inexistentes), ostentam três características comuns:

- um Estado com relativa autonomia, dotado de tecnocracia com razoável competência;

- um projeto nacional claro, que não se confunde com a idéia de que a macroeconomia correta é condição necessária e suficiente, correndo o resto por conta do automatismo do mercado, da integração passiva;

- sobretudo nos melhores exemplos, os da Ásia, a presença, desde o início, de forte componente distributivo de riqueza (reformas agrárias do pós-guerra no Japão, Coréia, Taiwan) e de renda.

Das melhores experiências emerge o padrão da inserção "virtuosa" na economia globalizada: no ponto de partida, tentar reduzir a desigualdade no acesso aos meios de produção (terra, crédito, educação). Utilizar vantagens comparativas em recursos naturais (borracha, estanho, óleo de palma na Malásia) ou mão-de-obra barata e hábil (China, asiáticos), ou ambas, para gradualmente, por meio da exportação de manufaturados, incorporar mais conteúdo tecnológico e valor agregado. Investir maciçamente em educação, tecnologia, recursos humanos, em alguns casos para chegar a economia de serviços (Hong Kong, Cingapura) ou elevar o grau de eficiência. Em quase todos os exemplos, buscar capturar parcela do dinamismo da demanda dos mercados externos a fim de gerar internamente empregos capazes de absorver com bons salários os marginalizados da economia rural. Foi por essa via que a Malásia, a Tailândia e a China reduziram substancialmente, de mais de $60 \%$ em níveis em torno de 10 a $15 \%$, a pobreza absoluta, com políticas de "ação afirmativa" ou "discriminação positiva" para promover grupos desfavorecidos como a população malaia em relação aos chineses, na Malásia. 
Em conseqüência, a resposta às perguntas formuladas no início do trabalho é afirmativa com qualificações. É difícil, mas possível, colocar a integração externa a serviço do desenvolvimento e da integração interna desde que se preserve a autonomia de um projeto nacional, dirigido de dentro e traduzido em processo gradual de inserção, mediante políticas ativas de competitividade também em nível microeconômico das empresas. Os exemplos concretos estão aí diante de nós.

\section{Conclusões realistas sobre o Brasil}

Não parece exagero postular que o país tem muitas condições para sair-se bem do desafio. A condição continental, a envergadura do mercado doméstico, o equilíbrio entre mercados externos comparáveis (EUA, Europa, América Latina, Ásia), a diversidade de recursos naturais insuficientemente explorados, conferem ao Brasil espaço de manobra não-disponível para a maioria das outras nações. Exceto em relação às graves disparidades sociais e regionais, ele sofre relativamente menos das mazelas que acompanham de hábito a personalidade dos monstros: pressão populacional como na China e na Índia, extraordinária heterogeneidade e às vezes hostilidade entre culturas, etnias, línguas e religiões, como nos dois gigantes asiáticos, na Indonésia e na Rússia. Devido à ausência de tradição de antagonismos com os vizinhos, é dos únicos países continentais a poder jogar a carta da integração regional. É este aspecto que se pode revelar decisivo pois acordos regionais, como o Mercosul ou sua possível ampliação com vistas a cobrir toda a América do Sul, oferecem um espaço protegido no interior do qual é mais fácil adquirir as condições de competitividade indispensáveis para concorrer num mercado mais acirrado: chegar ao global pelo regional.

Uma das condições para que tudo isso se realize é o Brasil superar a situação de retardatário em matéria de competitividade exportadora, característica que partilha com duas outras grandes nações em desenvolvimento, a Índia e a África do Sul. Em nosso caso, é em grande parte um problema de oferta: a pauta exportadora pouco mudou em 20 anos, estagnou em bens intermediários de pouco valor agregado, demanda pouco dinâmica e preços quase sempre declinantes. Contrariamente ao México e à China, tivemos pouco investimento, estrangeiro ou nacional, destinado especificamente a ampliar a capacidade exportadora e melhorar seu conteúdo tecnológico. A solução terá de passar, portanto, por uma política de investimentos e de tecnologia direcionados à conquista de mercados externos. Com a estabilidade econômica e o ajuste fiscal em vias de consolidação, desatado o nó da rigidez cambial e a tendência à redução gradual dos juros internos, estariam aparentemente criados alguns dos requisitos mínimos para a adoção de tal 
política. Ela depende adicionalmente de outros fatores insubstituíveis: o êxito da atual revisão modernizadora da política de governo em ciência e tecnologia, de investimento sistemático e maciço em recursos humanos e, acima de tudo, um conjunto de políticas sociais redistributivas e de geração de emprego, de eliminação da pobreza absoluta e redução significativa da desigualdade de riqueza e renda. Tais políticas não podem esperar pelo crescimento do bolo mas, ao contrário, devem constituir fatores integrais do dinamismo, mediante os ganhos decorrentes da expansão e integração do mercado doméstico. É esse o caminho da "integração virtuosa", a única capaz de inserir-nos na economia global e, ao mesmo tempo, ajudar-nos a integrar como produtores e consumidores de um mercado unificado os milhões de excluídos e marginalizados deixados por mais de quatro séculos de "integração perversa", condição para que eles se tornem cidadãos com plena participação. Só isso tornará inteiramente anacrônica a frase de Nabuco, de que o Brasil era país sem povo, pois um povo não podia ser formado de escravos. E apenas assim fecharemos o círculo vicioso da história de nossa inserção no mundo, superando em definitivo os últimos resquícios do sentido que teve a colonização entre nós.

Rubens Ricupero é secretário-geral da Conferência das Nações Unidas para o Comércio e o Desenvolvimento (Unctad), professor de Relações Internacionais na Universidade de Brasília e de História das Relações Diplomáticas no Instituto Rio Branco, DF. É autor, entre outros, dos livros O Brasil e o futuro do comércio internacional (1988), Brasil em mudança (1991), O futuro do Brasil (1992), O Brasil, a América Latina e os EUA desde 1930 (1993), A nova inserção internacional do Brasil (1994), Visões do Brasil (1995) e O ponto ótimo da crise (1998). 